\title{
Avoidable hospitalisation rates in Singapore, 1991-1998: assessing trends and inequities of quality in primary care
}

\section{Niti, T P Ng}

See end of article for authors' affiliations

\section{Correspondence to:} Dr T P Ng, Department of Community, Occupational and Family Medicine, National University of Singapore, Faculty of Medicine, 16 Medical Drive, Singapore 117597 ; cofngtp@nus.edu.sg

Accepted for publication 26 March 2002

\begin{abstract}
Study objectives: To assess avoidable hospitalisation as an indicator of quality of primary care by examining trends and gender and ethnic variations.

Design and setting: Aggregated nationwide data in Singapore from 1991 to 1998 were analysed for hospitalisations for chronic diseases that are avoidable by timely, appropriate, and effective primary care: asthma, congestive heart failure, chronic obstructive pulmonary disease, diabetes mellitus, and hypertension (avoidable hospitalisations).

Main results: Of a total of 1479494 hospitalisations, 6.7\% were for ambulatory care sensitive conditions (ACSC). The annual rate of avoidable hospitalisation was 29.4 per 10000 population. Women had lower rates of avoidable hospitalisations than men (22.4 versus 29.5 per 10 000), as well as for total hospitalisations (496.2 versus 515.5 per 10 000). Adjusted for total hospitalisation, men were 1.3 times more likely than women to be hospitalised for ACSC. With similar adjustments for baseline utilisation, Indian and Malays had 1.7 and 1.8 times higher rates of avoidable hospitalisations than Chinese. Avoidable hospitalisation decline was $-9.1 \%$ overall; greater in men $(-11.8 \%)$ than in women $(-5.3 \%)$; greater for Chinese $(-15.8 \%)$, than Malays $(-1.1 \%)$ and Indians (increase of $+4.3 \%)$.

Conclusion: Gender and ethnic differences and declining trends in avoidable hospitalisation demonstrated in this study suggest that avoidable hospitalisation rates are a sensitive indicator for assessing quality of primary ambulatory care.
\end{abstract}

t is generally recognised that hospitalisations for undesirable outcomes of care for chronic diseases can be avoided if timely, appropriate, and effective primary care is available. ${ }^{1-3}$ Hospitalisation rates for ambulatory care sensitive conditions (ACSC) such as hypertension, diabetes, chronic heart failure, chronic obstructive pulmonary disease, and asthma, for which hospitalisation could be avoided by good primary care, have been widely used as measures of access to primary care in the United States ${ }^{4-12}$ and in Spain. ${ }^{3}$

The island nation of Singapore (3.2 million, 77\% Chinese, $14 \%$ Malays, and $8 \%$ Indians) has undergone rapid and dramatic demographic and epidemiological changes over the past 40 years. Population aging and the increasing numbers of chronic degenerative diseases has led to rising demand for and costs of hospital services. In 1993, the white paper on Affordable Health Care highlighted the imperatives to make the healthcare system more effective and efficient. ${ }^{13}$ Rising healthcare costs can be contained by reducing the volume of hospitalisations that could be avoided through improved quality of primary care. However, since the restructuring of the healthcare system, there are limited data to evaluate the quality of primary care.

Potentially avoidable hospitalisations have been found to account for $3.2 \%$ to $12 \%$ of all hospitalisations, ${ }^{479}{ }^{10}$ with rates varying from 8.9 to 59 per 10000 populations, ${ }^{45}{ }^{11}$ depending on the definitions and number of medical conditions included. In the US, the rates of avoidable hospital admissions were greater in the black population, ${ }^{7}$ in those with lower levels of education and income, ${ }^{578}$ and those who are uninsured or under Medicaid. ${ }^{4}$ Women were less likely to be hospitalised ${ }^{8}$ although it is generally known that they report having more chronic conditions and more visits to health professionals. ${ }^{14}$ Thus far, there has only been one study that has examined trends in avoidable hospitalisation rates to evaluate the efficiency gains of a national health system. In the US, rates of avoidable hospitalisation have increased from 99.2 per 10000 population in 1980 to 133.8 per 10000 population in $1998 .^{12}$

In this study, we evaluated the use of avoidable hospitalisation as a performance indicator of the quality of primary care in Singapore. Issues of efficiency and equity in the health system were examined by examining trends in avoidable hospital admissions, and its variation by gender and ethnicity in Singapore between 1991 and 1998.

\section{METHODS}

\section{Background}

In Singapore, $80 \%$ of the volume of hospitalisations is provided through 10 public sector hospitals, while private sector hospitals provide the remaining $20 \%$. About $20 \%$ of primary health care is provided through 16 public sector polyclinics, which employ fixed salaried physicians, while the remaining $80 \%$ is provided through some 1900 private medical clinics run by general practitioners (GPs), who charge direct fees for services. Public medical services are provided to cater to the lower income groups who cannot afford the private sector charges, and are subsidised through general taxation. Charges of the public sector primary care services are subsidised by up to $50 \%$, (and up to $75 \%$ for the elderly population). The rates of copayment vary according to the quality of hospital accommodation chosen by the patients; in the lower classes or types of wards in the public hospitals, their hospitalisation expenses are subsidised up to $80 \%$ by the government.

As there are no strictly enforced regulatory or financing mandates for patients to obtain referrals for hospital care through their primary care doctors, patients therefore have direct access to hospital care services. Referrals of patients by 
Table 1 Distribution of avoidable hospitalisations by demographic characteristics, 1991-98

\begin{tabular}{|c|c|c|c|c|c|c|}
\hline \multirow[b]{2}{*}{ Characteristics } & \multicolumn{2}{|l|}{$<65$ years } & \multicolumn{2}{|c|}{$\geqslant 65$ years } & \multicolumn{2}{|l|}{ Whole } \\
\hline & $\begin{array}{l}\text { Number } \\
\text { of } \mathrm{AHs}\end{array}$ & $\%$ & $\begin{array}{l}\text { Number } \\
\text { of } \mathrm{AHs}\end{array}$ & $\%$ & $\begin{array}{l}\text { Number } \\
\text { of } \mathrm{AHs}\end{array}$ & $\%$ \\
\hline Total hospitalisations & 1127276 & & 352218 & & 1479494 & \\
\hline Avoidable hospitalisations (AHs) & 59155 & $5.25^{*}$ & 40807 & $11.6 *$ & 99962 & 6.8 \\
\hline \multicolumn{7}{|l|}{ Chronic condition } \\
\hline Asthma & 37615 & 63.6 & 3481 & 8.5 & 41096 & 41.1 \\
\hline Congestive heart failure & 7686 & 13.0 & 15774 & 38.7 & 23460 & 23.5 \\
\hline Chronic obstructive pulmonary diseases & 4688 & 7.9 & 15910 & 39.0 & 20598 & 20.6 \\
\hline Diabetes mellitus & 9101 & 15.4 & 5623 & 13.8 & 14724 & 14.7 \\
\hline Hypertension & 65 & 0.11 & 19 & 0.05 & 84 & 0.1 \\
\hline \multicolumn{7}{|l|}{ Gender } \\
\hline Male & 34064 & 57.6 & 22803 & 55.9 & 56867 & 56.9 \\
\hline Female & 25091 & 42.4 & 18004 & 44.1 & 43095 & 43.1 \\
\hline \multicolumn{7}{|l|}{ Age group (y) } \\
\hline$<15$ & 20300 & 34.3 & & & & \\
\hline $15-24$ & 3732 & 6.3 & & & & \\
\hline $25-44$ & 10554 & 17.8 & & & & \\
\hline $45-64$ & 24569 & 41.5 & & & & \\
\hline \multicolumn{7}{|l|}{ Ethnicity } \\
\hline Chinese & 33596 & 56.8 & 32065 & 78.6 & 65661 & 65.7 \\
\hline Indians & 9813 & 16.6 & 3844 & 9.4 & 13657 & 13.7 \\
\hline Malays & 15746 & 26.6 & 4898 & 12.0 & 20644 & 20.7 \\
\hline
\end{tabular}

private GPs into both public and private hospitals immediately confer the patient "full paying class" status without any subsidy. In view of the higher costs of hospital care arising from referral by this source, many referrals by private GPs of patients with limited ability to pay are routed via the public sector primary care outpatient clinics.

The vast majority of payments for hospital care $(80 \%)$ are made through the patient's own and/or family members' medical saving account (compulsory Medisave scheme). Patients may also make supplementary payments by voluntary medical insurance (Medishield, a national health insurance scheme, or other private insurance schemes). For patients who are unable to pay for their hospital charges, payment may be made through Medifund, the national healthcare fund of last resort for indigent patients. Thus, the healthcare system is a hybrid system sharing some elements of the public tax based national health system in the United Kingdom or Spain, and of the US system of private and insurance based healthcare financing.

The study was conducted using aggregated data on annual hospital admissions in Singapore from 1991 to 1998. The source of inpatient discharge data was the national database of the Central Claims Processing System (CCPS), a computerised system that began operation in 1991 to facilitate the submission of claims for hospital charges from all public and private hospitals in Singapore. All diagnoses were coded using International Classification of Disease-9 Clinical Modification (ICD-9 CM). We selected chronic conditions with severe exacerbations or specific complications for which hospitalisation is potentially avoidable, as in those studied by Bindman et al $^{3}$ (see appendix). We restricted the selection to these ACSC, because they account for a substantial proportion of the current changing disease pattern, and other studies that used these rubrics showed good evidence of a strong link between good management at the primary care level and hospitalisation rates. ${ }^{91}$ Data were also collected on the number of total hospitalisations, excluding maternity cases and psychiatric disorders. The mid-year population estimates were obtained from the Department of Statistics.

Data analysis was performed separately for two age groups, under 65 years old and 65 years and over. A previous US study $^{7}$ has found that factors associated with high rates of avoidable hospitalisation depend on age cohort, with the population aged 65 and over having much less variation in rates across socioeconomic backgrounds. Age adjusted hospitalisation rates were calculated by the direct standardisation method, using the general population of 1990 as standard.

Variations in rates of avoidable hospitalisations may also be explained by other broad unmeasured factors influencing healthcare utilisation, such as patient demand, treatment preferences, and physician practice pattern, which are reflected in rates of overall hospitalisation, which include, in the majority, non-avoidable hospitalisation conditions. To account for this "baseline utilisation" in comparing avoidable hospitalisation rates, we made adjustment by dividing each relative rate of avoidable hospitalisation by the relative rate of total hospitalisation. The avoidable hospitalisation rate adjusted for baseline utilisation, ${ }^{24}$ was calculated as follows:

$$
\begin{aligned}
& \text { Adjusted relative rate }=\left(\mathrm{AH} \text { Rate }_{\text {pop } \mathrm{A}} / \mathrm{AH} \text { Rate }_{\text {pop } \mathrm{B}}\right) /(\mathrm{TH} \\
& \text { Rate }_{\text {pop A }} \text { / TH Rate } \text { pop B }_{\text {l, }}
\end{aligned}
$$

where $\mathrm{AH}=$ avoidable hospital admission and $\mathrm{TH}=$ total (all cases) hospital admission.

The trends in avoidable hospitalisation rates were examined for single years, and the total decline from 1991 to 1998 was estimated from the parameters obtained by regression on calendar years.

\section{RESULTS}

From 1991 to 1998, of a total of 1479494 hospitalisations, $6.7 \%$ were considered potentially avoidable (table 1 ). This proportion was higher in the elderly age group 65 years and over (11.6\%) than in those under 65 years $(5.2 \%)$. The vast majority of hospitalisations were self referred $(88.6 \%)$.

\section{Analyses of population under 65 years of age}

Potentially avoidable hospitalisations in those aged below 65 years were mostly dominated by children aged below 15 $(34.3 \%)$ and people aged 45 to $64(41.5 \%)$, and by asthma $(63.6 \%)$. The average annual rate was 26.0 per 10000 population (table 2). Women had lower average rates of avoidable hospitalisations than men (22.4 versus 29.5 per 10000 population year), as well as for total hospitalisations (496.2 versus 515.5 per 10000 population year). Adjusted for total 
Table 2 Avoidable hospitalisation rates and adjusted rate ratios, population under 65 years of age, 1991-98

\begin{tabular}{|c|c|c|c|c|c|}
\hline & $\begin{array}{l}\text { Avoidable } \\
\text { hospitalisation } \\
\text { rate }\end{array}$ & $\begin{array}{l}\text { Total } \\
\text { hospitalisation } \\
\text { rate }\end{array}$ & $\begin{array}{l}\text { Avoidable } \\
\text { hospitalisations } \\
\text { as \% of total } \\
\text { hospitalisations ( }\end{array}$ & $\begin{array}{l}\text { Rate ratio } \\
(95 \% \mathrm{Cl})\end{array}$ & $\begin{array}{l}\text { Rate ratio (95\% } \\
\mathrm{Cl} \text { ) (adjusted for } \\
\text { total } \\
\text { hospitalisations) }\end{array}$ \\
\hline $\begin{array}{l}\text { Population under } \\
65\end{array}$ & 26.0 & 506.4 & 5.25 & & \\
\hline \multicolumn{6}{|l|}{ Gender } \\
\hline Female & 22.4 & 496.2 & 4.60 & 1.00 & 1.00 \\
\hline Male & 29.5 & 515.5 & 5.86 & $\begin{array}{l}1.36 \\
(1.30 \text { to } 1.43)^{*}\end{array}$ & $\begin{array}{l}1.29 \\
(1.24 \text { to } 1.35)\end{array}$ \\
\hline \multicolumn{6}{|l|}{ Age group (y) } \\
\hline$<15$ & 38.1 & 403.0 & 9.45 & 1.00 & 1.00 \\
\hline $15-24$ & 10.8 & 434.8 & 2.48 & $\begin{array}{l}0.28 \\
(0.26 \text { to } 0.31)^{*}\end{array}$ & $\begin{array}{l}0.26 \\
(0.24 \text { to } 0.28)^{*}\end{array}$ \\
\hline $25-44$ & 11.9 & 454.1 & 2.63 & $\begin{array}{l}0.31 \\
(0.29 \text { to } 0.33)^{*}\end{array}$ & $\begin{array}{l}0.29 \\
(0.28 \text { to } 0.31)^{*}\end{array}$ \\
\hline $45-64$ & 58.7 & 860.2 & 6.83 & $\begin{array}{l}1.54 \\
(1.46 \text { to } 1.62)^{*}\end{array}$ & $\begin{array}{l}0.72 \\
(0.70 \text { to } 0.75)^{*}\end{array}$ \\
\hline \multicolumn{6}{|l|}{ Ethnicity† } \\
\hline Chinese & 18.9 & 450.3 & 4.24 & 1.00 & 1.00 \\
\hline Indians & 59.3 & 824.9 & 7.43 & $\begin{array}{l}3.09 \\
(2.90 \text { to } 3.29)^{*}\end{array}$ & $\begin{array}{l}1.78 \\
(1.70 \text { to } 1.87)^{*}\end{array}$ \\
\hline Malays & 49.7 & 656.8 & 7.78 & $\begin{array}{l}2.59 \\
(2.45 \text { to } 2.73)^{*}\end{array}$ & $\begin{array}{l}1.81 \\
(1.71 \text { to } 1.91)^{*}\end{array}$ \\
\hline
\end{tabular}

hospitalisation, men were still 1.3 times more likely than women to be hospitalised for these conditions.

Compared with Chinese, Indian and Malays had higher annual rates of avoidable hospitalisations $(18.9,59.3$, and 49.7 per 10000 population respectively). Although Indians and Malays also had higher rates of total hospitalisations, compared with Chinese, they still had 1.8 times higher rates of avoidable hospitalisation, after adjusting for total hospital admission rates.

From 1991 to 1998, avoidable hospital admission rates declined by $22.9 \%$ - greater than the decline in total hospital admission rates $(-15.0 \%)$. Adjusted for total hospital admission, the rate of avoidable hospitalisation decline was $-9.1 \%$ (table 3, fig 1). This adjusted decline was greater in men (by $-11.8 \%$ ) than in women (by $-5.3 \%$ ); also greater in Chinese $(-15.8 \%)$, compared with Malays $(-1.1 \%)$, whereas Indians actually showed an increase of $+4.3 \%$ (table 3 , fig 1 ). In the Malay population, gender differences was most marked, with women showing a marked increase of $10.8 \%$, whereas men actually showed a decrease of $-11.9 \%$. In the Indian population, both genders showed an increase, but this was more marked in women $(8.1 \%)$ than in men $(0.9 \%)$.
Although avoidable hospital admissions were dominated by asthma, the ethnic differences in avoidable hospitalisation rates were consistently observed across all chronic conditions. Greater rates of avoidable hospitalisation in Indians and Malays were observed particularly for asthma, congestive heart failure, and diabetes.

\section{Analyses of population over $\mathbf{6 5}$ years of age}

Avoidable hospital admissions in the elderly population aged 65 year and above accounted for $40.8 \%$ of all avoidable hospital admissions or $11.6 \%$ of total hospital admissions (for all age groups). The average rate was 261.2 per 10000 populations (table 4), predominantly for chronic obstructive pulmonary disease (101.7 per 10000$)$ and congestive heart disease ( 100.9 per 10000 ). The rates of avoidable hospitalisations were also higher in Indians and Malays than in Chinese. From 1991 to 1998, avoidable hospitalisation rates in the elderly population increased by $11.2 \%$; however, after adjusting for total hospitalisations, avoidable hospitalisation in fact had been declining by $-3.3 \%$. Among the three ethnic groups, only the Chinese showed an adjusted decline of $-7.2 \%$, whereas

Table 3 Percentage changes in hospitalisation rates $†$, population under 65 years of age, 1991-98

\begin{tabular}{|c|c|c|c|c|c|c|c|c|}
\hline & \multicolumn{4}{|l|}{$\%$ Change } & \multicolumn{4}{|c|}{$\%$ Change (adjusted for total hospitalisation) } \\
\hline & Chinese & Indians & Malays & Total & Chinese & Indians & Malays & Total \\
\hline Total hospitalisations & $-14.7 * *$ & $-23.0 * * *$ & $-11.2 * *$ & $-15.0 * *$ & & & & \\
\hline Avoidable hospitalisations & -28.4 *** & $-19.9 * *$ & -12.1 & $-22.9 * *$ & $-15.8 * *$ & 4.3 & -1.1 & $-9.1^{*}$ \\
\hline \multicolumn{9}{|l|}{ Gender } \\
\hline Female & -29.2 ** & $-18.8 * *$ & -5.5 & -20.1 ** & $-17.0^{*}$ & $8.1^{*}$ & 10.8 & -5.3 \\
\hline Male & $-28.0 * * *$ & $-21.0 *$ & $-17.6^{*}$ & $-24.8 * *$ & $-15.0 * *$ & 0.9 & -11.8 & $-11.8 *$ \\
\hline \multicolumn{9}{|l|}{ Age group (y) } \\
\hline$<15$ & $-37.3^{* *}$ & $-43.3^{* *}$ & $-18.7^{*}$ & $-31.9 * *$ & $-24.3^{* *}$ & -20.5 & -15.6 & -20.1 * \\
\hline $15-24$ & -23.9 & 7.7 & 3.4 & -9.8 & -7.6 & $40.5^{*}$ & 18.6 & 9.2 \\
\hline $25-44$ & -38.1 ** & $-17.3^{*}$ & -10.8 & -23.6 ** & $-21.9 * *$ & $19.4^{*}$ & 8.6 & -3.9 ** \\
\hline $45-64$ & $-19.9 * *$ & -3.8 & -8.6 & $-17.0 * *$ & -11.7 & 2.5 & -8.9 & -9.3 \\
\hline \multicolumn{9}{|l|}{ Causes } \\
\hline Asthma & $-36.6^{* *}$ & $-26.8^{*}$ & $-18.6 *$ & -28.9 * * & -24.9 ** & -3.9 & -8.2 & $-15.8 *$ \\
\hline $\mathrm{CHF}$ & $21.6^{*}$ & $46.1^{*}$ & $48.9^{*}$ & 28.6 ** & $41.3^{* *}$ & 86.4 ** & 67.2 ** & 50.1 ** \\
\hline COPD & $-36.8 * * *$ & 29.2 & -20.4 & -30.6 ** & $-25.7^{* *}$ & $68.3^{*}$ & -9.9 & $-18.1^{*}$ \\
\hline $\mathrm{DM}$ & $-30.5^{\star *}$ & $-31.4^{* * *}$ & $-16.8^{*}$ & $-28.9 * \star *$ & -18.5 & -11.2 & -6.8 & $-16.4^{*}$ \\
\hline Hypertension & -6.8 & -19.0 & 15.8 & -4.0 & 13.4 & -0.1 & 28.4 & 15.6 \\
\hline
\end{tabular}



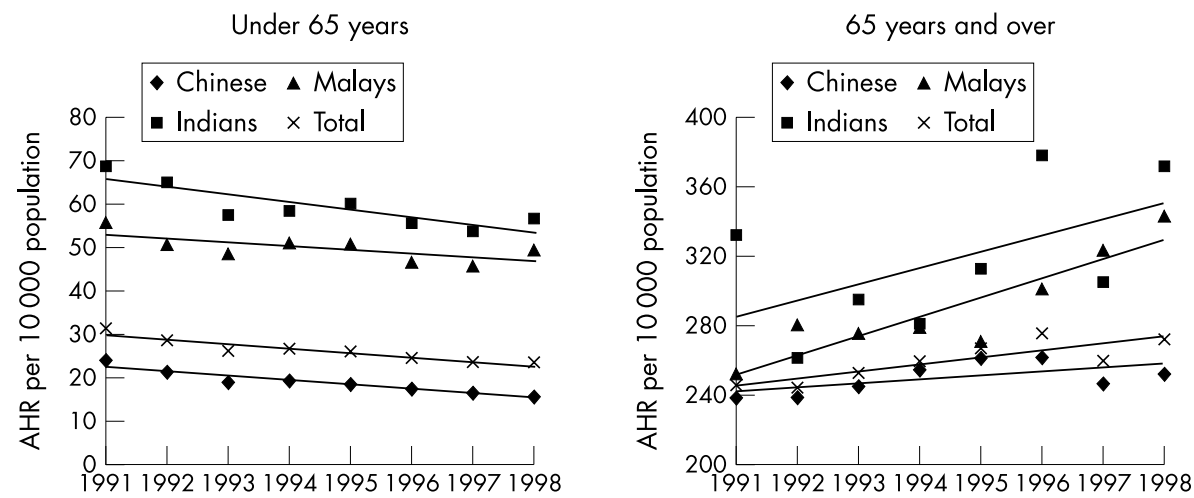

Figure 1 Trends in sex and age standardised avoidable hospitalisation rates (AHR) by ethnicity, Singapore, 1991-98.

\begin{tabular}{|c|c|c|c|c|c|c|c|}
\hline & \multicolumn{3}{|c|}{ Avoidable hospitalisation rates $\dagger$} & \multirow[b]{2}{*}{$\begin{array}{l}\text { Percentage } \\
\text { change }\end{array}$} & \multicolumn{2}{|c|}{$\begin{array}{l}\text { Total hospitalisation } \\
\text { ratest }\end{array}$} & \multirow{2}{*}{$\begin{array}{l}\text { Percentage } \\
\text { change } \\
\text { (adjusted) }\end{array}$} \\
\hline & $\begin{array}{l}\text { Average } \\
1991-1998\end{array}$ & 1991 & 1998 & & 1991 & 1998 & \\
\hline Chinese & 251.4 & 239.2 & 253.2 & +6.8 & 2138.2 & 2467.2 & $-7.3^{* *}$ \\
\hline Indian & 321.4 & 333.3 & 373.1 & +22.7 & 2196.6 & 2223.1 & +19.3 \\
\hline Malay & 293.6 & 251.6 & 343.7 & $+30.5^{* *}$ & 1656.1 & 2121.0 & +2.4 \\
\hline Total & 261.2 & 247.0 & 272.7 & $+11.2^{* *}$ & 2092.7 & 2410.2 & $-3.3^{*}$ \\
\hline
\end{tabular}

†Annual age and sex standardised rates per 10000 population. ${ }^{*} p<0.05 ;{ }^{*} p<0.01 ;{ }^{*}{ }^{*} p<0.001$.

Indians and Malays showed adjusted increases of $+19.3 \%$ and $+2.4 \%$ respectively.

\section{DISCUSSION}

The use of avoidable hospitalisation as a performance indicator of the quality of primary care should be predicated by the recognition that multiple factors contribute to hospitalisation rates. These include socioeconomic factors (gender, age, ethnicity, income, and insurance status ), ${ }^{3-11}$ disease incidence, prevalence and severity, ${ }^{5}$ perceived health need, access to care, propensity to seek care, ${ }^{515}$ availability of care including supply of primary care physician, ${ }^{6}{ }^{16}$ hospital bed availability, ${ }^{11}$ regular source of $\operatorname{care}^{1718}$ or continuity of care, ${ }^{19}$ physician practice style. ${ }^{5}{ }^{11}$ In so far as overall hospitalisation rates reflect the multiple influences of these unmeasured factors, this baseline utilisation adjustment minimised to some extent the confounding influences of such unmeasured factors.

An important characteristic of a performance indicator is that it must have the sensitivity to detect variations between population groups. This Singapore study revealed interesting ethnic variations in avoidable hospitalisation rates. Indians and Malays had consistently higher levels and less favourable trends of avoidable hospitalisations rates than Chinese. Higher national rates of avoidable hospitalisation have also been observed in the US black population compared with the white population, but was observed only in the population under 65 years of age. ${ }^{7}$

Ethnic differences in avoidable hospitalisations may be explained by income differences. Previous studies suggest that people residing in low income areas, ${ }^{57}$ or who are uninsured or under Medicaid ${ }^{4}$ have higher rates of potentially avoidable hospital admissions. Education has also been shown to be a significant factor, with people holding degrees being less likely to be hospitalised. ${ }^{8}$ This may be related to higher functional health literacy, manifested in the ability in reading prescription labels, following diagnostic test instructions, and understanding treatment directions. In this study, both income and educational level are probable factors that explain the observed ethnic differences in avoidable hospitalisation rates. Based on census data, Malays and Indians have lower income and educational levels than Chinese. In Singapore, it is generally believed that there are few financial barriers for Malays and Indians to access primary medical care, as highly subsidised care are available to all through the public sector primary care clinics. Nevertheless, it is possible that, as the copayment rates for visits to primary clinics are the same for all social classes and ethnic groups, financial barrier is by no means non-existent. The extent to which the less advantaged have greater barriers to primary care is uncertain. There are probably also cultural and language barriers to the receipt of good primary care for Malays and Indians that explain lower functional health literacy among them. Further studies are needed to investigate this hypothesis.

Disease prevalence has been shown to be an independent predictor of avoidable hospital admission rates in small area analyses in urban California. ${ }^{5}$ Other previous studies have, however, shown that disease prevalence accounts for only a small proportion of the differences in hospitalisation rates between low and high income populations. ${ }^{20}{ }^{21}$ In this study, there are reasons to believe that disease prevalence is a contributory factor for ethnic differences in avoidable hospitalisation rates. Malays and Indians have been shown to have higher prevalence of diabetes and hypertension ${ }^{22} 23$ and asthma $^{24}$ than Chinese. Risk factors like cholesterol, obesity, smoking, and physical activity also show similar ethnic differences. Among people with known diabetes, Malays showed the greatest proportion of patients with poor diabetes control (64.6\%), followed by Chinese (52.4\%), and Indians (45.8\%). Among people with known hypertension, Malays also had the highest proportion of patients with poor blood pressure control $(77.0 \%)$, followed by Indians $(73.2 \%)$ and Chinese $(69.0 \%)$. There is also evidence that Malays experience more morbidity from asthma, have poorer knowledge of their disease and medication, have lower level of self management skills, and make less use of an emergency room for asthma attacks. ${ }^{25}$ 


\section{Key points}

- Hospitalisations for ambulatory care sensitive chronic conditions are deemed avoidable, and may be used as a population indicator of the quality of primary care.

- Avoidable hospitalisations rates in Singapore have been declining from 1991 to 1998, suggesting improvement in quality of primary care.

- However, higher rates in women than in men, and in Malays and Indians compared with Chinese suggest persisting demographic and social inequities.

\begin{tabular}{|c|c|c|}
\hline \multicolumn{3}{|l|}{ Appendix } \\
\hline Cause & $\begin{array}{l}\text { ICD-9 } \\
C M\end{array}$ & Description \\
\hline Asthma & 493 & $\begin{array}{l}\text { Asthma with or without mention status } \\
\text { asthmaticus }\end{array}$ \\
\hline $\mathrm{CHF}$ & $\begin{array}{l}428 \\
402.0 \\
402.11 \\
402.91\end{array}$ & $\begin{array}{l}\text { Heart failure, including congestive heart failure } \\
\text { Malignant hypertensive heart disease with CHF } \\
\text { Benign hypertensive heart disease with CHF } \\
\text { Unspecified hypertensive heart disease With } \\
\text { CHF }\end{array}$ \\
\hline COPD & $\begin{array}{l}491 \\
492.0 \\
492.8 \\
494 \\
496\end{array}$ & $\begin{array}{l}\text { Chronic bronchitis (obstructive and mucopurulent) } \\
\text { Emphysematous bleb } \\
\text { Other emphysema } \\
\text { Bronchiectasis } \\
\text { Chronic airway construction, not elsewhere } \\
\text { classified }\end{array}$ \\
\hline DM & $\begin{array}{l}250.1 \\
250.2 \\
250.3 \\
251.0\end{array}$ & $\begin{array}{l}\text { DM with ketoacidosis } \\
\text { DM with hyperosmolarity } \\
\text { DM with other coma } \\
\text { Hypoglycaemic coma }\end{array}$ \\
\hline Hypertension & $\begin{array}{l}401.0 \\
402.0 \\
403.0 \\
404.0 \\
405.0 \\
437.2\end{array}$ & $\begin{array}{l}\text { Malignant essential } \mathrm{HT} \\
\text { Malignant hypertensive heart disease without } \\
\mathrm{CHF} \\
\text { Malignant hypertensive renal disease } \\
\text { Malignant hypertensive heart and renal disease } \\
\text { Malignant secondary HT } \\
\text { Hypertensive enchephalopathy }\end{array}$ \\
\hline
\end{tabular}

Gender inequality in health has been documented in many reports. Some gender inequalities manifest themselves as more women reporting having chronic conditions, poor health status, and restriction of activities, and more visits to health professional, but lower hospitalisation rate. ${ }^{14}$ This has been interpreted in some places as a manifestation of the inverse care law, where those in need of care most are not receiving it. ${ }^{14}$ On the other hand, in studies of continuing primary care of patients with chronic medical conditions, ${ }^{26}$ women as more avid consumers of health care, are more likely to receive earlier diagnosis, or to be treated earlier and more regularly, thus preventing hospitalisation. We believe in this study the latter probable explains our findings. In reports of one day morbidity surveys ${ }^{27}$ of private GPs' clinics and public sector primary care outpatient clinics, rates of doctor visits overall, and for diabetes and hypertensive disease in particular, were higher for women than for men. In population surveys, ${ }^{22}{ }^{23}$ apart for diabetes, the prevalence of hypertension, hypercholesterolaemia, and asthma is higher in men than in women. There is no information on the level of blood sugar or blood pressure control among people with known diabetes or hypertension by gender.

We observed significant declines in adjusted rates of avoidable hospitalisation, which cannot be viewed merely as a reflection of underlying trends in overall hospitalisations. This is in contrast with the rising trends of avoidable hospitalisa-

\section{Policy implications}

Health regulatory authorities at the national and regional levels involved in the evaluation of their healthcare systems should consider using avoidable hospitalisation rates for monitoring the effectiveness and efficiency of their primary care system. The evaluation requires a central computerised population based hospital information system, and can potentially be expanded to provide disaggregated information for specific population subgroups, including those with special needs for intervention.

tions observed in the US. While this may suggest improved quality of primary care, further studies are needed to confirm this. The observed decline in avoidable hospitalisation cannot be explained by changes in disease prevalence. National Health Surveys conducted in 1992 and repeated in $1998^{2122}$ have shown that the population prevalence of diabetes and hypertension, have in fact increased not decreased.

In our separate analysis of the elderly population aged 65 and above, we found again ethnic differences in avoidable hospitalisations. This is in contrast with the results from the study of the 1990 US population. ${ }^{7}$ In the US, improved access to primary care afforded by the Medicare programme may explain the narrow gap in avoidable hospital admission rates in the elderly population. As there is no equivalent care programme for the elderly population in Singapore, the same level of primary care access and quality may not exist for all socioeconomic groups in the population.

We have also observed that avoidable hospitalisation rates have increased in real terms in the elderly population. Although the elderly population have a different pattern of disease, for which the effectiveness of current medical care intervention may be more limited, factors related to access and quality of primary care should be further investigated.

In conclusion, gender and ethnic differences and differing trends in avoidable hospitalisation demonstrated in this study suggest that avoidable hospitalisation rates are a sensitive population indicator for assessing quality of primary ambulatory care.

\section{REFERENCES}

1 Starfied B. Primary care and health: a cross-national comparison. JAMA 1991;266:2268-71.

2 Millman M, ed. Institute of Medicine, Committee on Monitoring Access To Personal Health Care Services. Access to health care in America. Washington, DC: National Academy Press, 1993:11-14, 31-45, 102-106.

3 Casanova C, Starfield B. Hospitalizations of children and access to primary care: a cross-national comparison. Int J Health Serv 1995;25:283-94.

4 Weismann JS, Gatsonis C, Epstein AM. Rates of avoidable hospitalization by insurance status in Massachusetts and Maryland. JAMA 1992;268:2388-94.

5 Bindman AB, Grumbach K, Osmond D. Preventable hospitalizations and access to health care. JAMA 1995;274:305-1 1 .

6 Parchman ML, Culler S. Primary care physicians and avoidable hospitalization. J Fam Pract 1994;39:123-8.

7 Pappas G, Hadden WC, Kozak L, et al. Potentially avoidable hospitalizations: Inequalities in rates between US socioeconomic groups. Am J Public Health 1997;87:811-16.

8 Culler SD, Parchman ML, Przybylski M. Factors related to potentially preventable hospitalizations among the elderly. Med Care 1998;36:804-17

9 Gill JM. Can hospitalizations be avoided by having a regular source of care? Fam Med 1997;29:166-71.

10 Blustein J, Hanson K, Shea S. Preventable hospitalizations and socioeconomic status. Health Aff (Millwood) 1998;17:177-89.

11 Komaromy M, Lurie N, Osmond D, et al. Physician practice style and rates of hospitalization for chronic medical conditions. Med Care 1996;34:594-609.

12 Kozak LJ, Hall M, Owings MF. Trends in avoidable hospitalizations, 1980-1998. Health Aff (Milwood) 2001;20:225-32.

13 Ministerial Committee. White Paper: Affordable Health Care. Singapore: Singapore National Printers, 1993.

14 Fernandez E, Schiaffino A, Rajmil L, et al. Gender inequalities in health and health care services use in Catalonia (Spain). J Epidemiol Community Health 1999;53:218-22. 
15 Weinberger $M$, Oddone EZ, Henderson WG et al. Does increased access to primary care reduce hospital readmissions? N Engl J Med 1996;334:1441-7

16 Shea S, Misra D, Ehrlich MH, et al. Predisposing factors for severe, uncontrolled hypertension in an inner-city minority population. N Engl J Med 1992;327:776-81.

17 Hayward RA, Bernard AM, Freeman HE, et al. Regular source of ambulatory care and access to health services. Am J Public Health 1991:81:434-8.

18 Gill JM. Can hospitalizations be avoided by having a regular source of care? Fam Med 1997;29:166-71.

19 Mainous AG. Gill JM. The importance of continuity of care in the likelihood of future hospitalization: Is the site of care equivalent to a primary clinician? Am J Public Health 1998;88: 1539-41.

20 Billings J, Zeitel L, Lukomnik J, et al. Impact of socioeconomic status on hospital use in New York City. Health Aff (Millwood) 1993;12:162-73.
21 Wennberg JE. Population illness rates do not explain population hospitalization rates. Med Care 1987;25:354

22 Ministry of Health. National Health Survey 1992. Singapore: Singapore National Printers, 1993

23 Ministry of Health. National Health Survey 1998. Singapore: Singapore National Printers, 1999.

$24 \mathrm{Ng}$ TP, Hui HP, Tan WC. Prevalence of asthma and risk factors among Chinese, Malay, and Indian adults in Singapore. Thorax Chinese, Malay, and

$25 \mathrm{Ng}$ TP. Adult asthma prevalence, morbidity and mortality and their relationships with environmental and medical care factors in Singapore. Asian Pac J Allergy Immunol 1999;17:127-35.

26 Kotchen JM, Shakoor-Abdullah B, Walker WE, et al. Hypertension control and access to medical care in the Inner City. Am J Public Health 1998;88: 1696-9.

27 Emmanuel SC, Tan BY, Choo KW. 1993 Morbidity survey of outpatients. Singapore Family Physician 1994;20:75-91.

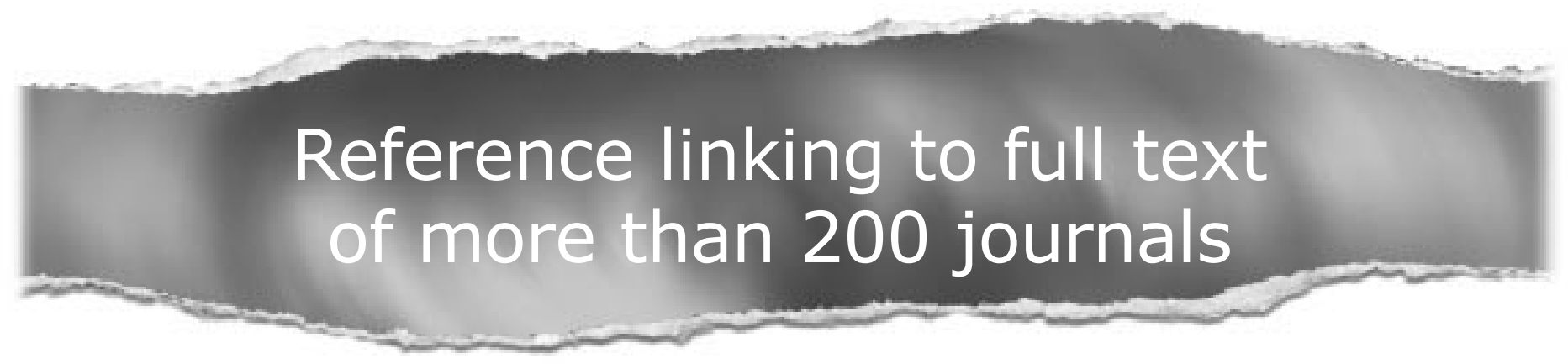

\section{Toll free links}

You can access the FULL TEXT of articles cited in the Journal of Epidemiology and Community Health online if the citation is to one of the more than 200 journals hosted by HighWire (http://highwire.stanford.edu) without a subscription to that journal.

There are also direct links from references to the Medline abstract for other titles.

www.jech.com 